\title{
Fuel removal from tile-gaps with oxygen discharges: reactivity of neutrals
}

\author{
Thomas Schwarz-Selinger*, Udo von Toussaint, Christian Hopf, Wolfgang Jacob \\ Max-Planck-Institut für Plasmaphysik, EURATOM Association, Boltzmannstr. 2, 85748 Garching, Germany
}

\begin{abstract}
Carbon removal in so-called remote areas, where no energetic species can reach the surface, is investigated with low-temperature glow discharges in pure oxygen. Plasma-deposited amorphous hydrogenated carbon thin films are used as a model system for redeposited films. Erosion measurements are performed on flat substrates as well as on two different 3D test structures. One design consists of $19 \mathrm{~mm}$ deep gaps with widths ranging from 0.5 to $4 \mathrm{~mm}$ to simulate ITER tile gaps. A second design consists of a flat box-like structure where particles can enter only through a narrow slit. Measurements are performed for substrate temperatures ranging from 290 to $580 \mathrm{~K}$. Erosion rates follow an Arrhenius-type dependence on substrate temperature with an effective activation energy of $0.25 \mathrm{eV}$. While at room temperature the surface loss probability of the dominant eroding species is $50 \%$ it becomes smaller at elevated temperatures. At elevated temperatures the films are not only removed faster but simultaneously erosion penetrates deeper into the gaps.
\end{abstract}

PACS numbers: 52.77.Bn, 52.77.Dq, 81.05.Uw, 81.15.Jj

Published in Physica Scripta: Received 3 June 2009

Accepted for publication 14 September 2009

Published 30 December 2009

Phys. Scr. T138 (2009) 014009 (8pp)

doi: 10.1088/0031-8949/2009/T138/014009

\section{INTRODUCTION}

Redeposition of carbon accompanied by co-deposition of hydrogen isotopes is expected to be the dominant fuel retention mechanism in the carbon phase of ITER [1-3]. To avoid continuous build-up of a fuel inventory inside the vessel, removal techniques need to be developed. Besides other removal techniques, e.g. mechanical removal and laser desorption and ablation techniques, oxygen glow discharge cleaning was proposed as one possible candidate to remove redeposited hydrocarbon films [1]. For removal of redeposited films from plasma-wetted areas and other locations that are accessible by remote handling, all these methods seem to be promising [410]. Especially for plasma oxidation, e.g. ASDEX Upgrade showed that removal is very effective even at room temperature $[10,11]$ and similar results were obtained in TEXTOR [8] for elevated temperatures. For HT-7 it was reported that at wall temperatures between 400 and $470 \mathrm{~K}$ oxygen glow discharge cleaning was more effective than thermal oxidation [7].

Apart from deposition of thick layers on plasma-exposed surfaces $[12,13]$ co-deposition in narrow gaps of castellated structures is a major concern [13-16]. Especially the side walls of gaps are expected to be the main deposition areas [12-16]. Also deposition far away from the first wall in socalled remote locations may contribute significantly to the total fuel build-up (see [2] and references therein). Of the particles created in the oxygen discharge ions are expected to be lost after the first wall collision but reactive neutrals could in principle penetrate deep inside gaps and migrate to remote locations. However, up to now no dedicated measure-

*Corresponding author. Tel.: +49 893299 1767; Fax: +49 89329996 1767, Email address: Thomas.Schwarz-Selinger@ipp.mpg.de ments were conducted in present fusion experiments to clarify to what extent it is possible to remove co-deposits from nonplasma-wetted and remote areas with oxygen glow discharge cleaning. So far, it is only known from the ASDEX Upgrade cleaning experiment that no substantial erosion was found in remote areas [10, 11].

Although removal of carbonaceous films by oxygen glow discharges is a standard tool in technological processes (see, e.g., [17-19]) little is known about the reactivity of individual species formed in oxygen-containing low-temperature plasmas as well as their specific role in the erosion process. It is known from laboratory experiments, that the ion energy as well as the substrate temperature significantly influence the erosion rate. This indicates that ballistic as well as chemical effects play a crucial role in the erosion process [20,21]. Energetic oxygen species cause erosion rates which exceed those of physical sputtering due to chemical reactions at the end of their range, a phenomenon known as chemical sputtering or reactive ion etching [22-24]. E.g. Baggerman et al. [25] reported measured yields for polymer etching in oxygen plasmas of up to $\approx 14$ removed carbon atoms per incident energetic oxygen particle. This implies that other reactive species in addition to the energetic ones participate in the erosion process. Hopf et al. demonstrated that a synergistic interaction between ions and molecular oxygen exists that can explain such high yields $[11,26]$. They devised a model that describes quantitatively the measured rates and their dependence on ion energy, ion and neutral fluxes and substrate temperature. According to that model one would expect that for temperatures below $650 \mathrm{~K}$ removal is only effective for surfaces with direct contact to the glow discharge where particles with substantial energies can reach the surface. For remote areas as well as narrow gaps one would expect largely reduced erosion compared to plasma-exposed surfaces.

In a recent study we exposed deep gaps with variable aspect ratio to different oxygen discharges at room temperature 
[27]. We found that removal of carbon layers inside the gaps is possible even if there is no direct plasma contact. However, the erosion rates inside the gaps are largely reduced compared to flat surfaces. Film removal deep inside the gaps was found to be inefficient. To elucidate the effectiveness of neutral oxygen species we focus in the present study on the erosion of carbonaceous films in remote areas with no plasma contact. Plasma-deposited amorphous hydrogenated thin films were used as a model system for redeposited films. Here we address two issues that were not investigated so far: first, the influence of the substrate temperature on the erosion rate and second the surface loss probability of the neutral species involved in the erosion process.

\section{EXPERIMENTAL}

Experiments were conducted with pure oxygen plasmas in the device PLAQ. A basic description of PLAQ is given in [20] and the present configuration is described in [27]. In short, PLAQ consists of a stainless steel chamber and is equipped with an electron-cyclotron-resonance (ECR) plasma source operating at $2.45 \mathrm{GHz}$. The ECR plasma is confined in a metallic cage, $150 \mathrm{~mm}$ in height and $140 \mathrm{~mm}$ in diameter. The power coupled to that volume is $75 \mathrm{~W}$. The chamber pressure is $1.0 \mathrm{~Pa}$. The distance between the bottom of the cage and the substrate holder is $100 \mathrm{~mm}$. For all the experiments presented in this article, the bottom of the plasma cage is closed with a solid plate so that the line of sight between the plasma and the substrate holder is blocked (see figure 1 in [27]). Particles can only leave the plasma through the side wall of the cage made of a metal mesh. They can reach the substrate only after several collisions in the gas phase or with the stainless steel walls. As energetic species are expected to loose their energy via these collisions, only reactive neutrals with thermal energies can reach the sample surfaces. Hence we refer to the substrate position in this study as remote position and to this experimental configuration as remote ECR discharge. For flat samples an in situ ellipsometer operating at $632.8 \mathrm{~nm}$ can be used to measure erosion and deposition rates at the center of the substrate holder in real time [28]. Heating of the substrates is performed by radiation from the backside by a Boralectric ${ }^{\circledR}$ heating element. For the room temperature measurements the substrate holder is water cooled to remove the thermal load from the plasma cage that heats up to $430 \mathrm{~K}$ during the exposures. Temperatures are measured with a type $\mathrm{K}$ thermocouple clamped to the substrates from the front side.

Three different types of sample geometries are used in this study as illustrated in figure 1 . Besides exposure of a flat sample, different 3D structures are exposed to the $\mathrm{O}_{2}$ discharge in the remote position. One is the so-called tile gap test structure (TGTS) already described in [27] where also a photograph is shown. The other one is a so-called cavity.

As a model system for co-deposited films, amorphous hydrogenated carbon thin films $(\mathrm{a}-\mathrm{C}: \mathrm{H})$ are used. They are deposited on single-crystalline silicon wafers (thickness $680 \mu \mathrm{m}$ ) on the driven electrode of a capacitively coupled $\mathrm{rf}$ plasma at $13.56 \mathrm{MHz}$. Methane is used as precursor gas at a
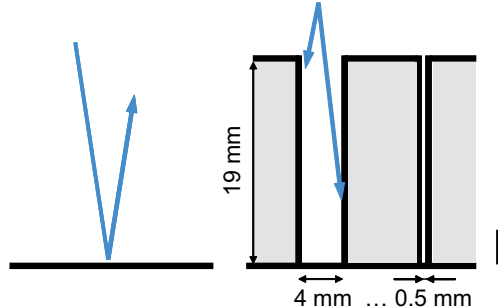

flat tile gap

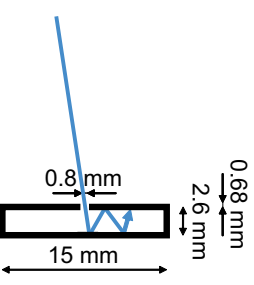

cavity
FIG. 1: Schematic representation of the sample geometries used in this study (to scale).

pressure of 2.0 $\mathrm{Pa}$ and a dc self-bias voltage of $-300 \mathrm{~V}$. Under these conditions typical dense a-C:H films with a hydrogen content $(\mathrm{H} /(\mathrm{H}+\mathrm{C}))$ of $30 \%$, refractive index $\hat{n}=2.12-i \cdot 0.08$ and carbon number density of $9 \times 10^{22} \mathrm{~cm}^{-3}$ are produced. For the erosion measurements on the flat substrates $\mathrm{a}-\mathrm{C}: \mathrm{H}$ films are directly deposited in the device PLAQ according to the recipe mentioned above. Growth and erosion are monitored in-situ with single wavelength ellipsometry at $632.8 \mathrm{~nm}$ in real time. For the 3D geometries samples are grown in a different setup, where the variation of the initial a-C:H film thickness is smaller than $1 \%$. For these films the lateral film thickness distribution on each wafer is analyzed before and after exposure by ellipsometry. A single wavelength ellipsometer (Jobin Yvon PZ 2000 operating at $632.8 \mathrm{~nm}$ ) equipped with an automated sample stage is used to perform 2-dimensional scans with a spot size of $10 \times 30 \mu \mathrm{m}$. The film thickness on the different wafers varies between 55 and $290 \mathrm{~nm}$, depending on the application. Cavities and tile gaps are placed in the center of the substrate holder to maintain axial symmetry. In these cases thickness changes cannot be monitored in real time during exposure. Based on measurements on flat samples, exposure times were set in such a way that a substantial part of the initial a-C:H film was eroded.

The TGTS geometry was chosen to be representative not only for the castellated structures but also for the gaps between tiles that may be much deeper. Widths range from 0.5 to $4 \mathrm{~mm}$ and the depth is $19 \mathrm{~mm}$. The TGTS consist of three copper cuboids $19 \times 32 \times 8 \mathrm{~mm}^{3}$ in size that separate the four pairs of samples. The different gap widths $g$ of $0.5,1,2$, and $4 \mathrm{~mm}$ between the a-C:H coated silicon samples are defined by pairs of small copper spacers $\left(g \times 19 \times 4 \mathrm{~mm}^{3}\right)$.

To measure the surface loss probability so-called cavity probes are exposed. Cavity probes were first introduced into the fusion community by Hopf et al. to determine the surface loss probability of neutral hydrocarbon species [29]. They were later applied in fusion experiments by Mayer et al. [30]. The reason why we prefer this geometry to measure the surface loss probability is discussed in the next section. Our cavity is a box-like arrangement $2.6 \mathrm{~mm}$ high, $15 \mathrm{~mm}$ wide and $30 \mathrm{~mm}$ long, with a $0.8 \mathrm{~mm}$ narrow slit as an entrance at the top as illustrated in the cross section in figure 1 . The dimensions are chosen such that gas phase collisions inside the cav- 
ity can be neglected. The four side walls of the cavity are closed, so that particles can enter or leave the cavity only via the slit. The bottom as well as the top are made of a-C:H coated $\mathrm{Si}$ wafers, while the small side walls are defined by the copper structure that separates the Si samples from each other and holds them in place.

\section{RESULTS}

\section{A. Temperature dependence}

For the in situ erosion measurements silicon substrates $\left(28 \times 28 \mathrm{~mm}^{2}\right)$ are screwed to the stainless steel sample holder to ensure good thermal contact. Before each erosion measurement a dense a-C:H layer of $70 \mathrm{~nm}$ thickness is deposited on the substrate holder of PLAQ using the deposition parameters mentioned above. Growth and erosion are monitored insitu with ellipsometry in real time. It is known that dense a-C:H films relax after deposition [31]. Therefore we wait for 30 minutes after each deposition before adjusting the substrate temperature to the desired value. Although film properties are not expected to change much in the temperature range below $650 \mathrm{~K}$ a slight increase in film thickness is observed when films are tempered. This thickness increase was observed earlier [32] and is attributed to a release of internal stress. We introduce oxygen into the chamber only after the ellipsometry signal settles. To check whether thermal oxidation of the deposited film causes a measurable erosion rate at the given pressure and temperature we wait for another hour before igniting the discharge. As expected from thermal oxidation experiments of a-C:H films [26, 33] no erosion is found for any of the temperatures investigated here.

Figure 2 shows the erosion rates measured on a flat surface exposed to the remote ECR discharge for different substrate temperatures. For each erosion measurement the whole $70 \mathrm{~nm}$ thick film was eroded and the time averaged rate is shown in figure 2 . At $290 \mathrm{~K}$ the erosion rate is $4 \times 10^{-4} \mathrm{~nm} / \mathrm{s}$. This is about two orders of magnitude smaller than for the direct plasma exposure at the same location (bottom plate open, sample at floating potential,i.e. mean ion energy $7 \mathrm{eV}$, maximum ion energy $10 \mathrm{eV}$ ). The erosion rate increases by two orders of magnitude to $4 \times 10^{-2} \mathrm{~nm} / \mathrm{s}$ when the temperature is increased from 290 to $580 \mathrm{~K}$. From the Arrhenius plot an effective activation energy of $0.25 \mathrm{eV}$ is determined. This effective activation energy has to be compared with $1.3 \mathrm{eV}$ and $1.7 \mathrm{eV}$ found for thermal oxidation of a-C:H [26] and graphite [34], respectively. Obviously, the reactive species produced in the plasma are much more reactive than molecular oxygen.

\section{B. Determining the surface loss probability}

The surface loss probability $\beta$ is defined as the probability that a particle does not survive a collision with the surface and is hence complementary to the reflection probability $r$. A growth species is lost either by sticking with the probability

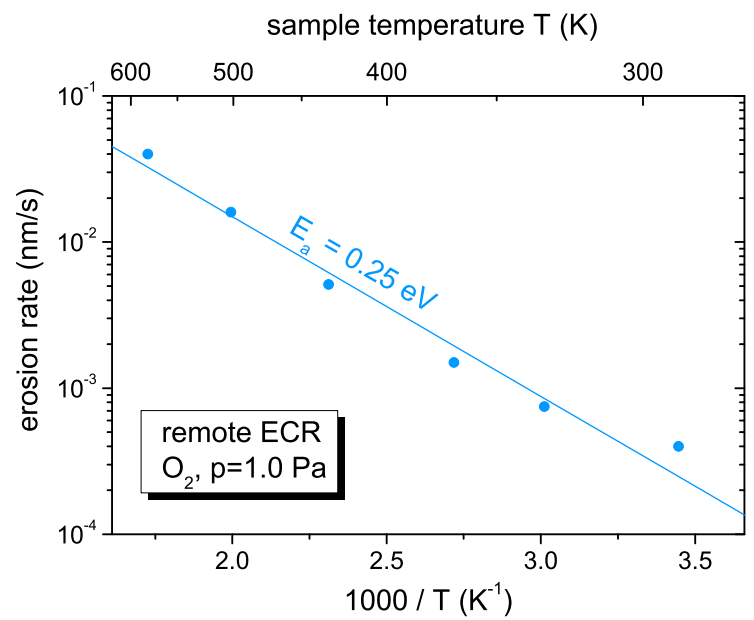

FIG. 2: Measured erosion rate for different substrate temperatures for the remote exposure of flat samples. For each measurement point a dense a-C:H layer with a thickness of $70 \mathrm{~nm}$ was eroded. Data are shown in form of an Arrhenius plot as function of 1000/T in logarithmic scale. The solid line corresponds to an effective activation energy of $0.25 \mathrm{eV}$.

$s$ to the surface or by recombination with an adsorbed surface atom with the probability $\gamma[29,35]$. While the reflection probability $r$ is also adequate to describe the interaction of eroding neutral species present in an oxygen plasma, $s$ and $\gamma$ and therefore also the meaning of $\beta$ need to be adopted. Instead of the sticking probability $s$ we define an erosion probability $\varepsilon$ that summarizes all possible reaction channels for a reactive oxygen species to interact with the film in such a way, that it leads finally to erosion. In $\gamma$ we summarize all probabilities that describe the loss of reactivity of eroding species. This might be recombination in the case of atomic oxygen or de-excitation in case of an excited $\mathrm{O}_{2}$ molecule or dissociation in case of ozone. Following this definition $\beta$ can be written as:

$$
\beta=1-r=\gamma+\varepsilon
$$

This is also schematically depicted in figure 3.

Figure 4 shows the probability that a reactive species escapes again from a certain substrate geometry as a function of the surface loss probability. For a flat geometry this escape probability is simply given by $1-\beta$. For arbitrary $3 \mathrm{D}$ structures it can only be derived numerically. We determined the escape probability by following particle trajectories inside the geometries. In a 2D Monte Carlo simulation the particles start along a line above the gap or cavity entrance with a cosine distribution. The transport inside the cavity is expected to follow consecutive adsorption-desorption cycles. Each desorption process is assumed to obey a cosine distribution. Figure 4 shows that both the TGTS and the cavity have a significantly lower escape probability than the flat surface. This is not surprising because on the flat surface a reactive species has only one chance to react with the surface, while in the 


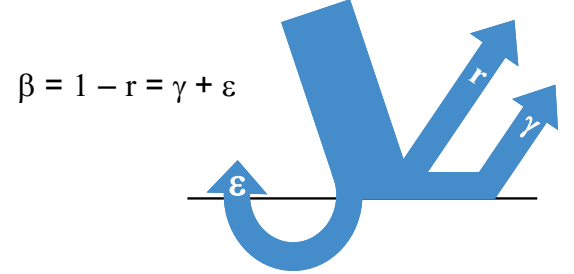

FIG. 3: Illustration of the surface loss probability $\beta$. When colliding with a surface species can be directly reflected with probability $r$, they can be converted with probability $\gamma$ to a non-reactive species or they can lead to erosion with the probability $\varepsilon$.

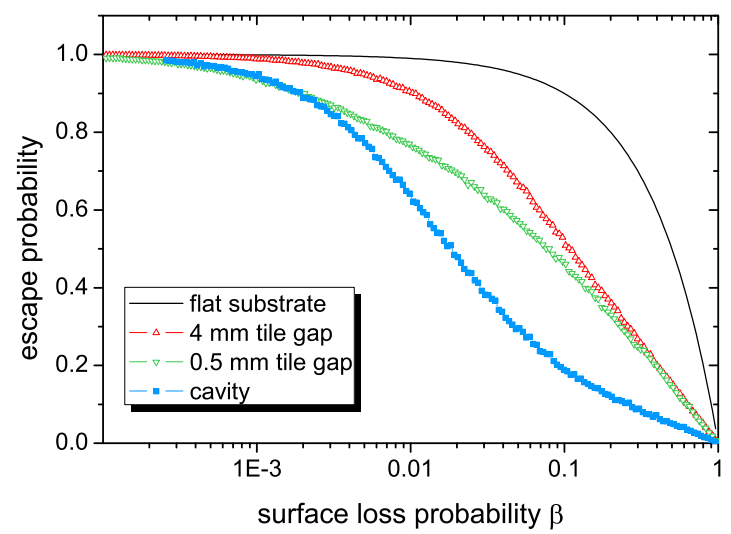

FIG. 4: Escape probability as a function of the surface loss probability for a flat substrate, $19 \mathrm{~mm}$ deep tile gaps with 0.5 and $4 \mathrm{~mm}$ gap width, and the cavity geometry shown in figure 1 .

TGTS and the cavity the particles have several surface collisions and therefore several possibilities to react. Figure 4 also shows that even for the narrow TGTS a much larger amount of the incoming particles leave the gap than in the case of the cavity. As a consequence the detection sensitivity for reactive species is higher in case of the cavity which holds true especially for low $\beta$ species. In addition, the erosion profile inside the TGTS is largely influenced by the initial angular distribution of the impinging reactive species because each surface element can be reached not only via collisions with the gap walls but also directly from outside the gap. For the cavity this is only the case for a rather limited area in the center of the bottom substrate opposite to the entrance slit. The inner side of the top substrate as well as the area far away from the center on the bottom substrate can only be reached after wall collisions and, therefore, they do not depend strongly on the initial angular distribution. The difference becomes most obvious when assuming a hypothetical erosion experiment with species that have a surface loss probability of 1 . In the case of the cavity one would directly see no erosion far away from the center on the bottom substrate as well as at the inner side of the top substrate. In the case of the TGTS one would just

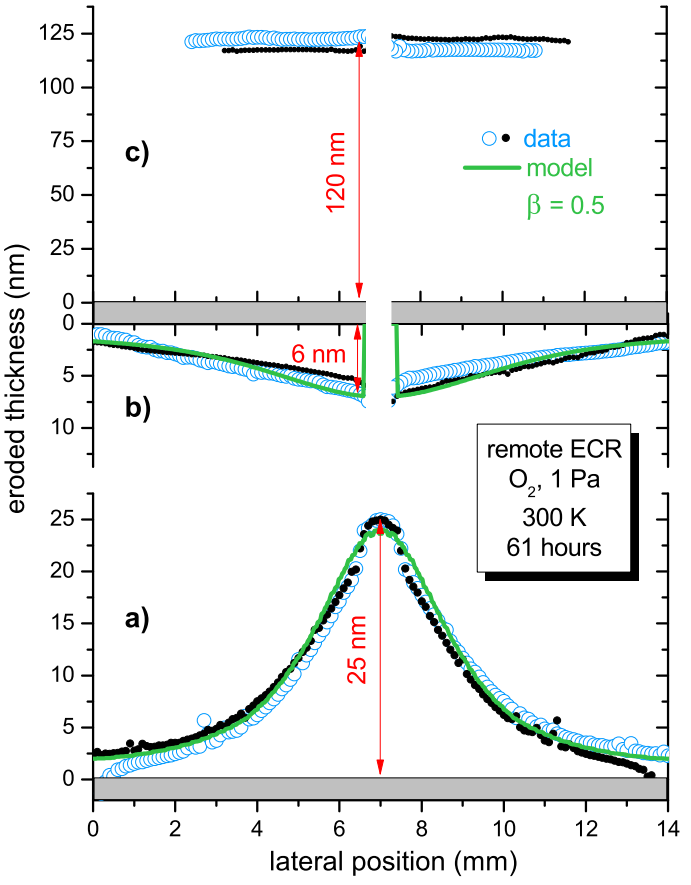

FIG. 5: Central scan of the eroded film thicknesses of the cavity a) at the bottom substrate as well as b) on the inner and c) on the outer side of the top substrate. The cavity was exposed to the remote ECR discharge in $1 \mathrm{~Pa}$ oxygen for 61 hours. Please note that while the thickness scale for a) and b) is the same it is compressed by a factor of five for c). The large open symbols and the small closed ones represent the same data just reflected at the central axis. The difference between the left and right sides gives an idea about the accuracy margin. The solid lines in a) and b) are the result of a fitted profile for species with $\beta=0.5$.

see a decrease in the erosion at the side walls of the TGTS as for any $\beta$ value. Because that decay depends strongly on the initial angular distribution of the species, which is not exactly known, the analysis would be ambiguous in this case. We therefore do not try to determine the surface loss probability from the TGTS measurements but only from the cavity experiments.

Figure 5 shows the erosion (a) at the bottom and (b) at the top substrate inside the cavity, as well as (c) at the outer side of the top substrate. The cavity was exposed for 61 hours to the remote ECR discharge in oxygen. Initial film thicknesses were 155,55 , and $290 \mathrm{~nm}$ on surfaces a, b, and c, respectively.

Even without discussing the exact shape of the measured profile, one can directly see that erosion inside the cavity is dominated by species with a relatively large surface loss probability. While $25 \mathrm{~nm}$ of the film is removed on the bottom surface of the cavity opposite to the entrance slit, only $6 \mathrm{~nm}$ is removed at the inner side of the top substrate. If species with low $\beta$ would dominate the erosion, a comparable amount should be eroded at the top and the bottom which is clearly not the case. The same conclusion can be drawn from the shape of the bottom profile. The strong decay from the center to the 
edge is in accordance with a high $\beta$ value. Obviously, most of the species get lost after very few collisions with the walls and therefore cannot reach areas far from the center.

Besides these qualitative arguments we can also derive a quantitative estimate for $\beta$ if we compare the eroded amount of material inside the cavity with that on the upper side of the cavity close to the entrance slit. For large $\beta$ values we can assume that reactive species cannot leave the cavity anymore but bounce back and forth until they are finally lost by wall collisions. Because they can be lost either by conversion to non-reactive species with probability $\gamma$ or by erosion processes with probability $\varepsilon$ only the fraction $\varepsilon / \beta$ leads to erosion. The amount of material eroded inside the cavity within a given exposure time $t$ is then given by

$$
N_{\text {inside }}=j_{\text {in }} \cdot A_{\text {slit }} \cdot t \cdot \frac{\varepsilon}{\beta} \text {, }
$$

where $j_{\text {in }}$ is the incoming reactive particle flux density and $A_{\text {slit }}$ is the area of the entrance slit. The amount of material $N_{t o p}$ that is eroded from the top of the cavity on a surface with area $A_{\text {slit }}$ is given by

$$
N_{\text {top }}=j_{\text {in }} \cdot A_{\text {slit }} \cdot t \cdot \varepsilon .
$$

The ratio between these two values is only determined by the surface loss probability $\beta$

$$
\frac{N_{\text {top }}}{N_{\text {tinside }}}=\beta,
$$

For finite $\beta$ values $j_{\text {in }}$ in equation (2) must be corrected with the escape probability shown in figure 4 . Without doing so equation (4) gives only a lower limit for $\beta$. For the $300 \mathrm{~K}$ exposure the erosion found on the upper side of the top layer (figure 5c) is $120 \mathrm{~nm}$. Taking into account the slit width of $0.8 \mathrm{~mm}$ and the length of $30 \mathrm{~mm}$, we can determine the hypothetically eroded amount on that area to be $2.9 \times 10^{6} \mu \mathrm{m}^{3}$. The total eroded amount inside the cavity is given by $6.1 \times 10^{6} \mu \mathrm{m}^{3}$ so that the ratio between these two values gives an estimate for $\beta$ of 0.5 . The error of that estimate can be determined from figure 4 . Less than $5 \%$ of the incoming species will be able to leave the cavity again and therefore the denominator in equation (4) is overestimated by $5 \%$.

In addition, we modelled the transport inside the cavity according to the model of Hopf et al. [36] to quantify the surface loss probability. In this model $\beta$ is assumed to be constant on all surfaces. Transport follows consecutive adsorptiondesorption steps, where the desorption is according to the cosine law. No gas phase collisions are considered but ballistic transport between the walls. As shown in figure $5 \mathrm{a}$ and $5 \mathrm{~b}$ a $\beta$ value of 0.5 describes the measured profile very well.

Figure 6 shows the erosion for a cavity exposed at elevated temperature for $30 \mathrm{~min}$. Apart from the temperature and the exposure time the experimental parameters were identical to those in figure 5. The temperature was adjusted to $540 \mathrm{~K}$. Comparing figure 6 with figure 5, one can directly see that the surface loss probability of the dominating species involved in the erosion process is smaller at elevated temperature. First, a similar thickness is eroded on the inner side of the top substrate compared to that at the bottom substrate, namely $25 \mathrm{~nm}$ compared to $39 \mathrm{~nm}$. Secondly, a substantial amount of material is eroded far from the center at the top and bottom substrates and consequently the profiles are less peaked than at $300 \mathrm{~K}$. Obviously, in this case the dominant species can survive much more wall collisions and reach areas far from the center. Comparing the integrals of the total eroded amount for the high temperature exposure case here $\left(1.4 \times 10^{6} \mu \mathrm{m}^{3}\right.$ outside versus $20 \times 10^{6} \mu \mathrm{m}^{3}$ inside the cavity) provides an estimate for $\beta$ of 0.07 . The escape probability is already $23 \%$ in this case, so that the correct $\beta$ value should be around 0.1 . The analysis of the shape with the Hopf model gives a best fit for a $\beta$ of 0.17 (see solid lines in figure $6 a$ and $6 b$ ). We can only speculate about the apparent difference here. The most probable explanation is that the temperature is slightly different for the top layer and inside the cavity in that experiment. As the cavity acts like a black body emitter the temperature inside the cavity is expected to be very homogenously distributed but probably slightly higher than at the outside. One indication for this is that erosion on the top surface is larger at the outer side where the substrates have thermal contact with the heated copper structure. Because of the strong dependence of the erosion rate on temperature (see figure 2) little deviations in temperature have a large effect on the rate.

\section{Erosion in tile gaps}

A TGTS was exposed to the remote ECR discharge for 48 hours. The initial film thickness was $140 \mathrm{~nm}$. The thickness variation was measured before and after exposure with ellipsometry in the middle of the side wall samples along the penetration depth. In addition, scans perpendicular to that direction along the upper and lower edges of the sample were performed. Because the spacers between the side wall samples cover the original film during exposure they locally prevent erosion. The resulting step edge between the eroded area and the initial film thickness can be used to check the central profile with an accuracy of $0.1 \mathrm{~nm}$. Figure 7 shows the eroded film thickness at the side wall TGTS substrates in logarithmic scale for four different gap widths. The entrance of the gap is at position 0 . For easier comparison with the following figure the displayed profiles are normalized to the maximum erosion observed at the side walls of the widest gap. Erosion is maximal at the entrance and decreases rapidly with increasing distance from the top in accordance with results we obtained earlier [27]. Other than in the previous experiment [27] the Si samples for the tile gap side walls were laser cut so that the edges were not only flush with the top but also with the bottom surface of the copper cuboids. We therefore have a more precise determination of the erosion profiles close to the bottom of the side walls. Erosion measured at the side wall close to the bottom and erosion measured at the bottom wafer coincide for all four gap widths. This was not the case in the previous experiment [27] when energetic particles reached the bottom surface. Also different from previous work [27], where a reference position was chosen as "flat, undisturbed surface" far 


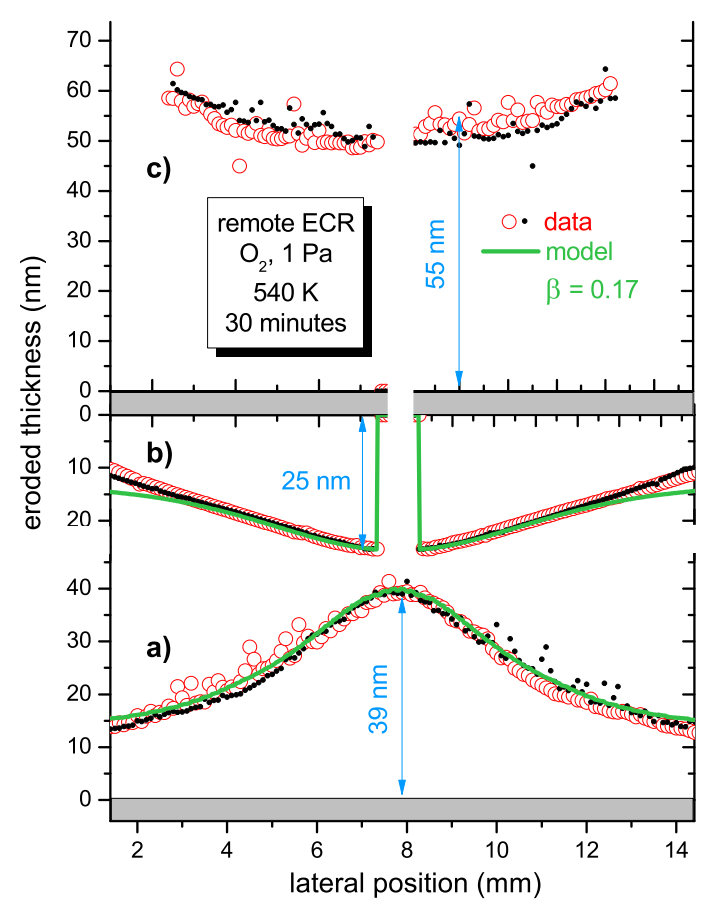

FIG. 6: Central scan of the eroded film thicknesses of the cavity a) at the bottom substrate as well as b) on the inner and c) on the outer side of the top substrate (c). The cavity was exposed to the ECR discharge in $1 \mathrm{~Pa}$ oxygen for 30 minutes. Thickness scale for a), b) and c) is the same. The large open symbols and the small closed symbols represent the same data just reflected at the central axis. The difference between the left and right sides gives an idea about the accuracy margin. The solid lines in a) and b) are the result of a fitted profile for species with $\beta=0.17$.

away from the TGTS, a substrate is now chosen as reference that is located next to the gap entrance on top of the TGTS. The eroded thickness on that substrate was $148 \mathrm{~nm}$. For all gap widths the maximum erosion - ranging from $80 \mathrm{~nm}$ for the $4 \mathrm{~mm}$ wide gap down to $39 \mathrm{~nm}$ for the $0.5 \mathrm{~mm}$ wide gap - is smaller than that reference value. The maximum erosion is largest for the widest gap. The erosion rate initially decays nearly exponentially with the distance from the gap and shows a tail that penetrates deeper inside the gap.

A second TGTS was exposed to the remote ECR discharge at elevated temperature $(470 \mathrm{~K})$. Apart from the temperature and the exposure time the experimental parameters were identical to the previous experiment (figure 7). Figure 8 shows the eroded film thickness at the side wall TGTS substrates in logarithmic scale for the four different gaps for this case. Also in this case the erosion at the side walls drops with the distance from the gap entrance. However, the particles survive more wall collisions and can penetrate deeper, as expected from the cavity experiments. Compared to the $300 \mathrm{~K}$ case, decay lengths are much larger. While the 1/e decay length scales roughly as the gap width for the $300 \mathrm{~K}$ case it is many times the gap width at $470 \mathrm{~K}$. The difference becomes even more pronounced, when comparing the total amount eroded inside

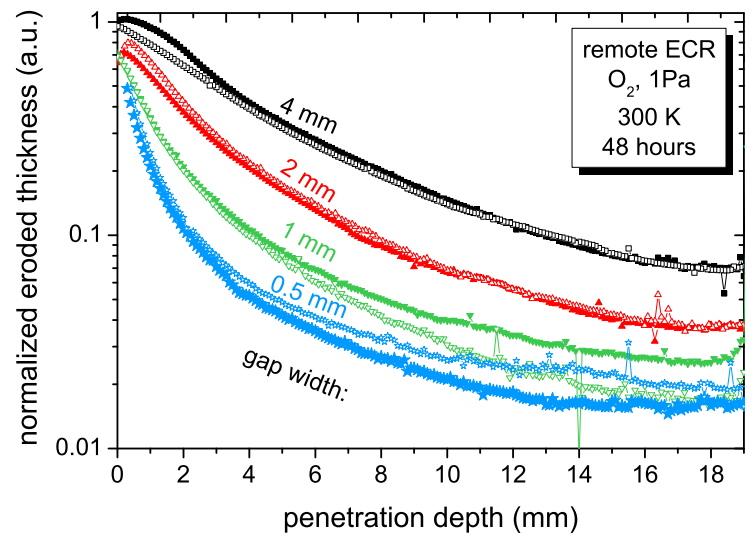

FIG. 7: Erosion at the side walls of the TGTS in logarithmic scale as a function of the distance from the gap entrance, normalized to the maximum side wall eroded thickness of $80 \mathrm{~nm}$. Shown are ellipsometry measurements for the four different gap widths exposed remotely for 48 hours at $300 \mathrm{~K}$ to the ECR plasma in oxygen at $1 \mathrm{~Pa}$. Open and closed symbols represent the left and right side walls, respectively.

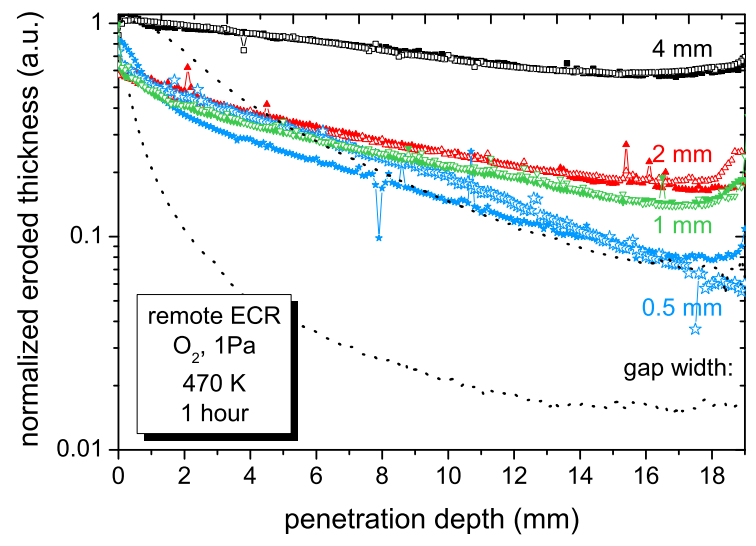

FIG. 8: Erosion at the side walls of the TGTS in logarithmic scale as a function of the distance from the gap entrance, normalized to the maximum side wall eroded thickness of $30 \mathrm{~nm}$. Shown are ellipsometry measurements for the four different gap widths exposed remotely to the ECR plasma in oxygen at $1 \mathrm{~Pa}$ for 1 hour at $470 \mathrm{~K}$. Open and closed symbols represent the left and right side walls, respectively. In addition the measurements for the 4 and $0.5 \mathrm{~mm}$ wide gap from figure 7 are shown as dotted lines for comparison.

the gaps. E.g., for the $0.5 \mathrm{~mm}$ wide gap the eroded amount per hour of exposure increases by two orders of magnitude from $4.6 \times 10^{4} \mu \mathrm{m}^{3}$ at $300 \mathrm{~K}$ to $4.6 \times 10^{6} \mu \mathrm{m}^{3}$ at $470 \mathrm{~K}$. 


\section{CONCLUSIONS}

Erosion of a-C:H films exposed to oxygen ECR discharges in remote positions, where no energetic oxygen species can reach the surface, is studied. The erosion rate increases exponentially with the substrate temperature with an effective activation energy of only $0.25 \mathrm{eV}$. The surface loss probability of the dominant erosion species is determined with cavity probes. Not only the absolute erosion rate, but also the surface loss probability of the dominant species depends strongly on temperature. The erosion rate increases by two orders of magnitude when the substrate temperature is increased from 290 to $580 \mathrm{~K}$. While the surface loss probability of the dominant erosion species is rather high at room temperature $(0.5)$, it decreases by about a factor of five when the temperature increases to $540 \mathrm{~K}$. As a consequence of both effects, films do not only get removed faster but simultaneously erosion penetrates deeper inside the gaps at elevated temperatures.

One explanation for the two different surface loss probabilities is that for the two investigated temperatures two different species are dominating the erosion. While at low temperature only few species with high surface loss probability prevail, erosion at higher temperature is governed by species that are more abundant and show a lower surface loss probability. From our present experiments we cannot conclude which reactive neutral species is responsible for the erosion. This might be atomic oxygen as well as ozone or exited oxygen molecules, but is appears that the dominant reactive species at $300 \mathrm{~K}$ and at elevated temperature are different. The conclusions of this work should be also valid for other low temperature discharge types applied in fusion experiments if they operate at similar pressure and with electron temperatures of a few $\mathrm{eV}$ because for these conditions the same reactive neutrals are supposed to be produced.

Taking into account that recent experiments in DIII-D, Textor, ASDEX Upgrade, and JT-60-U [14, 16, 37] showed deposition profiles with 1/e decay lengths that are typically a few times the gap width, one can conclude from our experiments, that cleaning of remote areas with oxygen glow discharges can be successful at elevated temperatures but will be ineffective at room temperature as the surface loss probability of the species dominating the erosion process is too large. The optimal strategy to remove redeposited carbon films by oxygen glow discharges in future fusion devices would be to operate at the highest temperature possible.
[1] G. Counsell, P. Coad, C. Grisolia, C. Hopf, W. Jacob, A. Kirschner, A. Kreter, K. Krieger, J. Likonen, V. Philipps, J. Roth, M. Rubel, E. Salancon, A. Semerok, F.L. Tabares, and A. Widdowson. Tritium retention in next step devices and the requirements for mitigation and removal techniques. Plas. Phys. Control. Fusion, 48:B189-B199, 2006.

[2] W. Jacob. Redeposition of hydrocarbon layers in fusion devices. J. Nucl. Mater., 337-339:839, 2005.

[3] J. Roth, E. Tsitrone, A. Loarte, Th. Loarer, G. Counsell, R. Neu, V. Philipps, S. Brezinsek, M. Lehnen, P. Coad, Ch. Grisolia, K. Schmid, K. Krieger, A. Kallenbach, B. Lipschultz, R. Doerner, R. Causey, V. Alimov, W. Shu, O. Ogorodnikova, A. Kirschner, G. Federici, A. Kukushkin, EFDA PWI Task Force, ITER PWI Team, Fusion for Energy, and ITPA SOL/DIV. Recent analysis of key plasma wall interactions issues for ITER. J. Nucl. Mater., 390-391:1-9, 2009.

[4] C.H. Skinner, N. Bekris, J. P. Coad, C.A. Gentile, and M. Glugla. Tritium removal from JET and TFTR tiles by a scanning laser. J. Nucl. Mater., 313-316:496, 2003.

[5] K.J. Gibson, G.F. Counsell, C. Curran, M.J. Forrest, M.J. Kay, and K.G. Watkins. The removal of co-deposited hydrocarbon films from plasma facing components using high-power pulsed flashlamp irradiation. J. Nucl. Mater., 337-339:565-569, 2005.

[6] A. Widdowson, J.P. Coad, N. Bekris, G. Counsell, M.J. Forrest, K.J. Gibson, D. Hole, J. Likonen, W. Parsons, T. Renvall, M. Rubel, and JET-EFDA Contributors. Efficacy of photon cleaning of JET divertor tiles. J. Nucl. Mater., 363-365:341345, 2007.

[7] J. S. Hu, J. G. Li, X. M. Wang, Y. P. Zhao, and HT-7 Team. Oxidation for deposits removal and hydrogen release on HT-7. J. Nucl. Mater., 363-365:862-869, 2007.

[8] V. Philipps, G. Sergienko, A. Lyssoivan, H. G. Esser, M. Freisinger, A. Kreter, and U. Samm. Removal of carbon layers by oxygen glow discharges in TEXTOR. J. Nucl. Mater.,
363-365:929-932, 2007

[9] C. Hopf, W. Jacob, and V. Rohde. Oxygen glow discharge cleaning in nuclear fusion devices. J. Nucl. Mater., 374:413421, 2008.

[10] C. Hopf, V. Rohde, W. Jacob, A. Herrmann, R. Neu, J. Roth, and ASDEX Upgrade Team. Oxygen glow discharge cleaning in ASDEX Upgrade. J. Nucl. Mater., 363-365:882-887, 2007.

[11] C. Hopf, M. Schlüter, and W. Jacob. Chemical sputtering of carbon films by argon ions and molecular oxygen at cryogenic temperatures. Appl. Phys. Lett., 90:224106 p1-p3, 2007.

[12] B. Pégourié, C. Brosset, E. Tsitrone, A. Beauté, S. Brémond, J. Bucalossi, S. Carpentier, Y. Corre, E. Delchambre, C. Desgranges, P. Devynck, D. Douai, G. Dunand, A. Ekedahl, A. Escarguel, E. Gauthier, J.P. Gunn, P. Hertout, S.-H. Hong, F. Kazarian, M. Kočan, F. Linez, Y. Marandet, A. Martinez, M. Mayer, O. Meyer, P. Monier-Garbet, P. Moreau, P. Oddon, J.-Y. Pascal, F. Rimini, J. Roth, F. Saint-Laurent, F. Samaille, S. Vartanian, C. Arnas, E. Aréou, C. Gil, J. Lasalle, L. Manenc, C. Martin, M. Richou, P. Roubin, and R. Sabot. Overview of the deuterium inventory campaign in Tore Supra: Operational conditions and particle balance. J. Nucl. Mater., 390-391:550-555, 2009.

[13] E. Tsitrone, C. Brosset, B. Pégourié, E. Gauthier, J. Bouvet, J. Bucalossi, S. Carpentier, Y. Corre, E. Delchambre, L. Desgranges, D. Douai, A. Ekedhal, A. Escarguel, Ph. Ghendrih, C. Grisolia, A. Grosman, J. Gunn, S.H. Hong, W. Jacob, F. Kazarian, M. Kočan, H. Khodja, T. Loarer, Y. Marandet, A. Martinez, M. Mayer, O. Meyer, P. Monier Garbet, P. Moreau, J.Y. Pascal, B. Pasquet, F. Rimini, H. Roche, I. Roure, S. Rosanvallon, P. Roubin, J. Roth, F. Saint-Laurent, F. Samaille, and S. Vartanian. Deuterium inventory in Tore Supra: Reconciling particle balance and post mortem analysis. In IAEA, editor, Fusion Energy 2008, Proceedings of the 22nd IAEA Fusion Energy Conference,, pages EX/9-1, Geneva, Switzerland, October 
13-18, 2008 2008. IAEA, Vienna, 2008.

[14] K. Krieger, W. Jacob, D.L. Rudakov, R. Bastasz, G. Federici, A. Litnovsky, H. Maier, V. Rohde, G. Strohmayer, W.P. West, J. Whaley, C.P.C. Wong, and The ASDEX Upgrade and DIII-D Teams. Formation of deuterium-carbon inventories in gaps of plasma facing components. J. Nucl. Mater., 363-365:870-876, 2007.

[15] D.L. Rudakov, W. Jacob, K. Krieger, A. Litnovsky, V. Philipps, W.P. West, C.P.C. Wong, S.L. Allen, R.J. Bastasz, J.A. Boedo, N.H. Brooks, R.L. Boivin, G. De Temmerman, M.E. Fenstermacher, M. Groth, E.M. Hollmann, C.J. Lasnier, A.G. McLean, R.A. Moyer, P.C. Stangeby, W.R. Wampler, J.G. Watkins, P. Wienhold, and J. Whaley. DiMES studies of temperature dependence of carbon erosion and re-deposition in the lower divertor of DIII-D under detachment. Phys. Scripta, T128:29_ 34, 2007.

[16] A. Litnovsky, P. Wienhold, V. Philipps, K. Krieger, A. Kirschner, D. Matveev, D. Borodin, G. Sergienko, O. Schmitz, A. Kreter, U. Samm, S. Richter, U. Breuer, and TEXTOR Team. Investigations of castellated structures for ITER: The effect of castellation shaping and alignment on fuel retention and impurity deposition in gaps. J. Nucl. Mater 2009, 390-391:556-559, 2009.

[17] M. A. Hartney, D. W. Hess, and D. S. Soane. Oxygen plasma etching for resist stripping and multilayer lithography. J. Vac. Sci. Technol. B, 7:1, 1989.

[18] S. Steudel, K. Myny, S. De Vusser, J. Genoe, and P. Heremans. Patterning of organic thin film transistors by oxygen plasma etch. Appl. Phys. Lett., 89:183503, 2006.

[19] C.-C. Liu, P. F. Nealey, Y.-H. Ting, and A. E. Wendt. Pattern transfer using poly(styrene-block-methyl methacrylate) copolymer films and reactive ion etching. J. Vac. Sci. Technol. B, 25:1963, 2007.

[20] B. Landkammer, A. von Keudell, and W. Jacob. Erosion of thin hydrogenated carbon films in oxygen, oxygen/hydrogen and water plasmas. J. Nucl. Mater., 264:48, 1999.

[21] W. Jacob, B. Landkammer, and C.H. Wu. Removal of codeposited layers by ECR discharge cleaning. J. Nucl. Mater., 266269:552, 1999.

[22] E. Hechtl, J. Bohdansky, and J. Roth. Sputtering behavior of graphite and molybdenum at low bombarding energies. J. Nucl. Mater., 123:1431, 1984.

[23] A. Refke, V. Philipps, E. Vietzke, M. Erdweg, and J. von Seggern. Interaction of energetic oxygen with different boron/carbon materials. J. Nucl. Mater., 212-215:1255-1259, 1994.

[24] W. Jacob and J. Roth. Chemical sputtering. In R. Behrisch and W. Eckstein, editors, Sputtering by Particle Bombardment IV, volume 110 of Topics in Applied Physics, chapter Chemical Sputtering, pages 329-400. Springer Verlag, Berlin, 2007.

[25] J. A. G. Baggerman, R. J. Visser, and E. J. H. Collart. Ioninduced etching of organic polymers in argon and oxygen radiofrequency plasmas. J. Appl. Phys., 75:758-769, 1994.

[26] C. Hopf, M. Schlüter, T. Schwarz-Selinger, U. von Toussaint, and W. Jacob. Chemical sputtering of carbon films by simultaneous irradiation with argon ions and molecular oxygen. New J. Phys., 10:093022 (27pp), 2008.

[27] T. Schwarz-Selinger, F. Genoese, Ch. Hopf, and W. Jacob. Carbon removal from tile-gap structures with oxygen glow discharges. J. Nucl. Mater., 390-391:602-605, 2009.

[28] W. Fukarek and A. von Keudell. Rev. Sci. Instrum., 66:3545, 1995.

[29] C. Hopf, K. Letourneur, W. Jacob, T. Schwarz-Selinger, and A. von Keudell. Surface loss probabilities of the dominant neu- tral precursors for film growth in methane and acetylene discharges. Appl. Phys. Lett., 74:3800, 1999.

[30] M. Mayer, V. Rohde, A. von Keudell, and ASDEX Upgrade Team. Characterisation of deposited hydrocarbon layers below the divertor and in the pumping ducts of ASDEX Upgrade. $J$. Nucl. Mater., 313-316:429, 2003.

[31] A. von Keudell and W. Jacob. Surface relaxation during plasmaenhanced chemical vapor deposition of a-C:H films, investigated by in-situ ellipsometry. J. Appl. Phys., 81:1531, 1997.

[32] K. Maruyama, W. Jacob, and J. Roth. Erosion behavior of soft, amorphous deuterated carbon films by heat treatment in air and under vacuum. J. Nucl. Mater., 264(1-2):56-70, 1999.

[33] W. M. Wang, W. Jacob, and J. Roth. Oxidation and hydrogen isotope exchange in amorphous, deuterated carbon films. $J$. Nucl. Mater., 245:66-71, 1997.

[34] M. Balden, K. U. Klages, W. Jacob, and J. Roth. Oxidative erosion of graphite in air between 600 and $1000 \mathrm{~K}$. J. Nucl. Mater, 341(1):31-44, 2005.

[35] J. Perrin, O. Leroy, and M. Bordage. Contrib. Plasma Phys., 36:3, 1996.

[36] C. Hopf, T. Schwarz-Selinger, W. Jacob, and A. von Keudell. Surface loss probabilities of hydrocarbon radicals on amorphous hydrogenated carbon film surfaces. J. Appl. Phys., 87:2719, 2000.

[37] K. Sugiyama, T. Tanabe, K. Masaki, and N. Mia. Tritium distribution measurement of the tilegap of JT-60U. J. Nucl. Mater., 367-370:1248, 2007. 